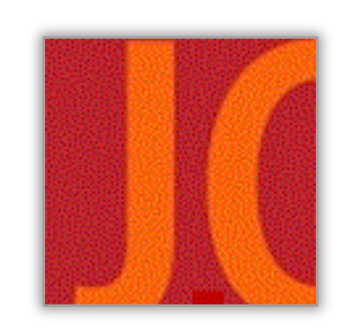

\title{
A Walking Curriculum: Learning From Risk and Connection
}

\author{
Astrid Steele \\ Nipissing University
}

\begin{abstract}
:
The act of walking has been described as "an exquisitely coordinated and elegant falling forward and catching oneself" (Kabat-Zinn, 2013, p. 125). Each step that we take is a physical risk in which we surrender our bodies into space, and only when our feet (re)connect with the earth do we find stability and are able to move forward. I propose that risk and connection are critical elements of a walking curriculum within an environmental education course for teacher candidates. The concept of risk is explored, and I describe a variety of course activities that involve taking physical, emotional or professional risks. The concept of connection is also examined with a particular focus on humans as integral to the natural world; and again, I describe course activities that provide opportunities for teacher candidates to experience connections to the natural world and to each other. Environment as the third teacher is explored, and lastly I reflect on my position as the instructor who facilitates learning opportunities for the teacher candidates in our course.
\end{abstract}

Keywords: environmental education; risk; connection; curriculum; teacher development 


\section{Un Programme de marche : apprendre du risque et de la connexion}

\section{Résumé :}

L'acte de marcher a été décrit comme « une chute en avant et un rattrapage merveilleusement coordonnés et élégantes » (Kabat-Zinn, 2013, p. 125). Chaque pas que nous faisons est un risque physique dans lequel nous abandonnons notre corps dans l'espace, et ce n'est que lorsque nos pieds se (re)connectent à la terre que nous trouvons la stabilité et sommes capables d'avancer. Je propose que le risque et la connexion sont des éléments essentiels d'un programme de marche dans le cadre d'un cours d'éducation à l'environnement pour les candidats enseignants. Le concept de risque est exploré et je décris une variété d'activités de cours qui impliquent la prise de risques physiques, émotionnels ou professionnels. Le concept de connexion est également examiné avec un accent particulier aux humains en tant que partie intégrante du monde naturel; et encore une fois, je décris des activités du cours qui offrent aux étudiants au programme de formation à l'enseignement la possibilité d'expérimenter des liens avec le monde naturel et entre eux. L'environnement en tant que troisième enseignant est exploré, et enfin je réfléchis à ma position en tant qu'instructeur qui facilite les opportunités d'apprentissage pour les candidats enseignants dans notre cours.

Mots clés : l'éducation environnementale; le risque; la connexion; le curriculum; le développement des enseignants 


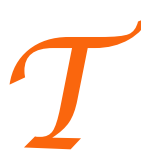

he act of walking has been described as "an exquisitely coordinated and elegant falling forward and catching oneself" (Kabat-Zinn, 2013, p. 125). Each step that we take is a physical risk in which we surrender our bodies into space, and only when our feet (re)connect with the earth do we find stability and are we able to move forward. My intention in this paper is to explore curriculum through the lenses of risk and connection-to question how teaching and learning can be enriched by both uncertainty and by building interconnected relationships - as a way to move forward in understanding ourselves within the world.

I love to walk in the bush that surrounds my home in Northern Ontario; it is a peaceful time in which I immerse myself in the cool, green rustling of the forest, the soft air around me, the brushing of leaves against my limbs and the almost mystical birdcalls. Walking grounds me and reconnects me to the natural world. It allows me time to think, to declutter my mind and simplify the problems that sometimes complicate my life. It was while walking that I began to think about risk and connection as a way to understand the teaching and learning that have been the focus of my career in education. I began to think about my teaching praxis as a walking curriculum, not only because we do some walking in my environmental education courses, but also because there are elements of walking that significantly inform my teaching and learning.

Having taught in a variety of settings, both alternative and formal, ranging from the elementary through the secondary panel, my most recent teaching and learning has been with teacher candidates in a faculty of education in Ontario, Canada. My area of specialization and passion include science education and environmental education, and it is my work with teacher candidates in these courses that provides food for thought and examples for this discussion. The teacher candidates in my classes have already achieved an undergraduate degree and are enrolled in the two-year teacher education program at the university. Most of them do not have a specialization in science or environmental studies; nonetheless, they are required to do some coursework in these areas as a way to prepare them for the many possibilities their teaching careers might present.

The environmental education course is intended as a way for teacher candidates to explore environmental issues, both globally and locally, and to find connections for teaching about those issues within the Ontario curriculum. The teacher candidates are strongly encouraged to connect environmental education to subjects beyond science and geography courses, where environmental education has traditionally been housed. With some encouragement, the teacher candidates have embedded environmental education in music lessons, math lessons and art lessons, among other subjects. A requirement of the course is that, during each class, we all go outside to participate in an outdoor activity. Our university campus has plenty of green space: a pond bordering on a forest and trails throughout. It is a perfect place to begin a (re)connection to nature for the teacher candidates. Of course, many of our activities require some walking or hiking or snowshoeing, and so my thinking about a walking curriculum is grounded in the many outdoor experiences that I have had with students of all ages, including the teacher candidates in the environmental education course. In this paper, I will focus on the concept of a walking curriculum as a way of understanding how the elements of risk and connection can transform teaching and learning. 


\section{Risk}

As our teacher candidates originate from various geographical areas, many of them do not have meaningful attachments to outdoor activities, so the very idea of taking students out of the classroom into natural spaces is daunting. It seems risky on a number of levels: students may be uncomfortable, or worse, become injured; parents may complain to the principal; curriculum objectives might not be achieved; and time may be wasted.

As teachers, we are trained to avoid risk for our students. We don't like to lose control of our teaching and learning environments; a loss of control is the ultimate risky behaviour. This has become particularly evident in our schools where rules abound to the point that, in some cases, very little outdoor play is allowed any more and field trips are limited.

One perceives risk when something valued comes under threat (Howard, 2011). For example, it is risky to walk in the woods around campus because we might encounter a bear. Or, it is risky to initiate a class discussion on a difficult topic such as evolution because opposing views may cause dissension, anger and hurt feelings. Yet, an activity that may seem very risky for some is appealing to others (Renn, 2004). Because we have always lived with the uncertainty that risk presents (whether physical, mental or emotional), risk assessment is necessarily a part of our evolutionary past (Slovic et al., 2004). As humans, we assess risk in two ways: based on logic, through which we calculate the possibilities of harm; or based on affect, by which we attend to our emotions and feelings regarding the risky behaviour. Remarkably, although logic is an important part of risk assessment, most people rely on their affective assessment of risk. "Although analysis is certainly important in some decisionmaking circumstances, reliance on affect and emotion is a quicker, easier, and more efficient way to navigate in a complex, uncertain, and sometimes dangerous world" (Slovic et al., 2004, p. 313). If it turns out that the risky experience is pleasurable and successfully navigated, then the activity is deemed less risky, and the perceived risk is considered acceptable (Howard, 2011; Slovic, 2000). The opposite is also true, whereby fears and experiences of discomfort or harm will prevent someone from engaging in what appears to be a risky activity (Ibid).

By surrounding ourselves with technology, we have mitigated perceived risks (Renn, 2004). However, I believe that in so doing, we have also deprived ourselves of direct experiences of the natural world. For example, it seems easier to stay in the climate-controlled comfort of the classroom when studying the ecology of frogs, even though this might be so much better accomplished at the local pond. Yet, Howard (2011) suggests, "change and innovation are not possible without taking risks" (p. 261). I have come to understand that it is important for teacher candidates to experience the risks of out-of-classroom teaching and learning so that they will feel a greater sense of comfort in taking their own students out of the classroom. After all, it is in the spaces outside of the traditional classroom that so much genuine learning can take place.

As an instructor, I decide whether to undertake certain activities based on my analysis of the perceived risks. I use logic and evidence of past successful experiences to evaluate the risk of an activity for my teacher candidates. I take into account whether or not the benefits of outdoor 
experiential learning and having fun are worth the risk. For example, in the activity, Hug-A-Tree, ${ }^{1}$ we walk to a wooded area on campus and the teacher candidates form groups of three or four with one person blindfolded. The other members of the group gently guide the blindfolded person in a wandering route through the forest and stop at a random tree. The blindfolded person then takes time to familiarize themselves with the tree, feeling its trunk, roots and limbs. Once the blindfolded person is satisfied that he/she/they could recognize the tree, the group members carefully walk back to the starting point, where the blindfold is removed, and the person is asked to identify the specific tree from the many in the forest.

What are the risks here? It is possible that the blindfolded person may stumble and injure themselves. It is possible that a group may wander out of earshot, or intentionally try to harm the blindfolded person. There may be mosquitoes, it may be too hot outside, or too cold. There is a risk that the activity may not support curriculum. However, in my experience, all of these risks can be mitigated: the weather is taken into consideration; clear instructions are given about how the group is to behave; safety is paramount; and boundaries in the forest are established. In the end, the benefits far outweigh the risks.

In the ensuing discussion of how the teacher candidates found their tree, they talk about the texture of the bark, the size of the trunk, the limbs and branches and roots; they recall the direction of sounds, of sunlight and wind, the rise and fall of the landscape, and stones they had to step over. They also remark on the trust they felt as they were led through the forest. Without prompting the teacher candidates have become attuned to the nature of the forest space in which our game took place. As their instructor, I recognize the benefits of the game: they have built a deeper level of trust and communication with their colleagues; they have challenged their sense memories; and they have discussed how this activity might be undertaken with their own students.

Because risk perceptions are more strongly influenced by affective emotions than analytical evaluation (Slovic, 2000), teacher candidates are more likely to be influenced by their feelings about teaching environmental education and about taking students out of their comfort zones than by making a logical decision to do so. For this reason, it is much more effective to take teacher candidates out of the classroom into natural environments to participate in hikes and activities, than to simply talk about them in the classroom. There is a strong need for teacher candidates to experience walking in nature and playing a game like Hug a Tree with success and enjoyment, in order to accept the risk of taking their own students out of the classroom to engage in a similar activity. Further, if I prepare teacher candidates for what the risk might look or feel like, then they are better prepared to accept the risk.

For example, most teacher candidates in my classes have never been snowshoeing, so their first experience with this activity will take them out of their physical and emotional comfort zones.

\footnotetext{
${ }^{1}$ While the Hug-A-Tree activity is found in a number of sources, for example, Coyote's Guide to Connecting with Nature (2010) by Ellen Haas, Evan McGown and Jon Young, I have been using this game for decades in my teaching practice, so have not sourced it specifically.
} 
Before we go snowshoeing, we spend time in preparation, learning about snowshoes, their history, the various models and materials of construction and how they are fastened. We discuss what clothing to wear, as a way to increase the physical comfort of the participants, and we also review strategies for group management outdoors. When the snowshoeing day finally arrives, there is a lot of excitement, and some trepidation, at the prospect of a new activity in a season most teacher candidates happily spend indoors. Once our snowshoes are securely fastened, we begin walking, pacing out our names in the snow, playing tag or running short relay races. The focus is transferred from the awkwardness of moving in deep snow while wearing overs-sized tennis rackets, to cheering for the team and creating beautiful letters in pristine snow. Realizing that they can manage the physical aspects of snowshoeing, teacher candidates begin the walk into the forest where we talk about the winter landscape, how life in the forest adjusts itself to the season, to the cold and to the blanket of snow. We explore the pukaq, that extraordinary layer of life that exists between the forest floor and the bottom of the snowpack; here, the temperature hovers around $1^{\circ} \mathrm{C}$, allowing insects, voles, moles and other small critters to scurry about their business in the half light. The teacher candidates marvel at so much life beneath their feet.

But, as teachers are well aware, risks in teaching and learning are not confined to physical activities in outdoor settings; indeed some of the most difficult risks are those we take when we challenge our students' ways of thinking about their world. Topics such as climate change, evolution, logging and consumerism can trigger considerable conflict amongst students with varying world views. Thus, lessons learned from walking in the forest-preparing, observing, listening, reflectingbecome important ways to connect to others, to understand their thinking during difficult conversations. For example, in a scenario in which groups of teacher candidates are stranded on an island, they are tasked to build a tower (out of one sheet of cardstock and some tape) by which to send a radio signal for assistance. This sort of activity is typically designed as a STEM (science, technology, engineering and math) exercise and delivered without contextualization. However, part way through the tower building process, I let the teacher candidates know that they are actually on an island inhabited by a group of Indigenous people. I ask them to consider the possible social and environmental scenarios and consequences of their presence on the island. Remarkably, they envision multiple storylines based on their own understanding of the Canadian history of colonization, and they manage to list numerous environmental detriments resulting from their presence on the island.

Introducing an Indigenous context into the STEM activity integrates environmental education into the realms of social and environmental justice, one of the many currents in the larger flow of environmental learning (Sauvé, 2005). An important element of environmental education is its integration in multiple subject areas, with the aim of encouraging attunement to the interconnectedness of human knowledge and human agency (Steele \& Ashworth, 2017). 


\section{Connection}

Let's return to the act of walking. Having taken the risk of letting our bodies fall forward into space, it is when our foot (re)connects with the earth that we regain our balance and consider the next step. We talk about being grounded as a feeling of well-being, emotional balance and a commonsense approach to life's challenges, but this expression is more than metaphorical; indeed, Braun and Dierkes (2017) consider a connection to earth/nature to be fundamental to human existence. Russel and Bell (1996) identify our integral connection to nature inasmuch as they speak to how poorly we attend to our sensory responses, such as smells and sounds, light and dark, with the result that "we tend to ignore the evidence of our own experience" (p. 177). Yet, these are the very connections by which we confirm our existence within nature, and which I, as an environmental education instructor, want teacher candidates to experience. As Russel and Bell claim, "one of our goals as environmental educators is to challenge such devaluation of embodied knowledge and to celebrate with students the fact that we are living, breathing creatures with profound ties to the natural world" (p. 177). Our attunement with nature is built into our DNA, but we must claim it.

Braun and Dierkes (2017) suggest there are two aspects to humans' relationship with nature: an emotional aspect-that is, having feelings towards the natural environment; and an aspect of selfidentity-that is, perceiving oneself as being part of, not separate from, the natural world. Moreover, Braun and Dierkes' research shows that the more time one spends in nature, the more intense one's connections within nature become, both the emotional connections and the perception that one is an integral part of the natural world. For this reason, I strive to be outside the classroom with the teacher candidates for at least 20 minutes during all of our sessions together, excepting only dangerous weather conditions, for example, thunderstorms. The teacher candidates learn to prepare for outdoor conditions, whether that means wearing raincoats and rubber boots, or parkas, mitts and warm hats, or using bug spray and sunscreen. We need to experience nature in all of its seasons and variations. During those times spent outdoors, we walk the forest paths. The walk itself is appreciated by the teacher candidates as they speak of a sense of relief to be outdoors, in fresh air and amongst the trees: "The natural world has the ability to effortlessly hold our attention (i.e., soft fascination) and restore our cognitive resources" (Fabjański \& Brymer, 2017, p. 2).

Our outdoor time provides opportunities to embark on explorations that allow us to attune to the languages and lessons of nature. Indeed, environments in which learning might take place are described by Carter (2007) as the third teacher; a "communicator and shaper of values" (p. 25). When we consider the many environments, both natural and human-wrought, in which we and our students engage in teaching and learning, we find there are any number of experiences that influence our perceptions. The third teacher consists of all the spaces in which we teach and learn. I often ask teacher candidates to observe what our classroom looks like and then to walk portions of our campus, both inside and out; in doing so, they are requested to consider how various elements

of those learning spaces might impact the teaching and learning that takes place. Are those spaces welcoming? Are they physically attractive and comfortable? Do they inspire curiosity? Do they provide quiet spaces for reflection? Carter (2007) tells us that "in environments that are beautiful, 
soothing, full of wonder and discovery, [students] feel intrigued, respected, and eager to spend their days living and learning in this place" (p. 25). As educators, once we realize that the natural environment is a third teacher and an important element of teaching and learning, then we understand the need to take our students out into natural spaces for lessons that we cannot teach on our own. These lessons may not be just about nature itself; the environment as the third teacher provides opportunities to connect with peers, colleagues, teachers and friends, and, in this way, is educative. Reconsider the trust required to walk blindfolded through the forest guided by one's peers in the Hug-A-Tree activity, the exhilaration of snowshoeing wildly towards your cheering team mates, or the need to thoughtfully navigate difficult conversations prompted by social and environmental injustices: a walking curriculum embraces the connections and interrelationships inherent in a deep connection to the natural world of which humans are truly a part.

As part of my walking curriculum, I sometimes assign teacher candidates to identify a number of trees and plants using field guidebooks or the mobile application iNaturalist. We talk about the value of identifying parts of nature, how learning the name of a tree gives it an identity not easily dismissed. We also consider the value of thumbing through field guides and observing the minute details of a specimen, versus allowing a digital application to do the work for us. In either case, we become very familiar with a small part of nature. Clifford Geertz (1996) points out that "no one lives in the world in general" (p. 259). We connect to the specific because we experience the specific. In connecting to a place in nature by learning about it, we become attuned to the place, and we begin to realize that we are part of a it; it shapes us, and we shape it-and that is the basis of culture (Greenwood, 2009). Lucy Sauvé (2005) explains: "The woven fabric of the environment can be understood to be the network of life itself, at the juncture between nature and culture. The environment serves as the crucible where our identity is forged through our relations of otherness" (p. 326). Arne Naess (1989) takes the idea of personal identity in relation to nature to the point where the two merge: "The ecosophical outlook is developed through an identification so deep that one's own self is no longer adequately delineated by the personal ego or the organism. One experiences oneself to be a genuine part of all life" (p.174).

All too often we think and teach about nature as though it were an object, such that when we study the human relationship with nature, we study how humans as subjects respond to or influence nature as an object. But, as Fabjański and Brymer, (2017) remind us, "people are part of nature and therefore at a fundamental level being human is also being nature. ... Returning to nature and remembering that we are nature is essential for health and wellbeing" (p. 2). As a way to be within nature, the instructions for the Curiosity Hike require teacher candidates to wander through an environment outside the classroom and take three pictures of subjects or situations about which they could ask questions. I ask teacher candidates to formulate questions that are more complex than "What kind of plant is this?" or "Why is this plant dying in this particular spot?" The teacher candidates then share their pictures and questions with their classmates, which often result in interesting discussions in which teacher candidates share their knowledge of the subject. The Curiosity Hike is a provocation for individual teacher candidates to observe and wonder about 
environment and to make their own connections. As Mullenbach et al. (2019) observe, "unimpeded interaction [with nature is] an opportunity to organically connect with nature" (p.365).

However, there are times when moving through places in nature, no matter how slowly one walks, is still too fast. There are times when one must come to a standstill. There is a wonderful connection between the Stoic tradition of the philosopher state and spending time in nature, as expressed by Fabjan'ski and Brymer, (2017), who describe "an embodied process of attuning to nature, which engages both mind and body" (p. 3).

The SitSpot activity functions in this spirit. The teacher candidates are required to go outside to a SitSpot-somewhere that they can sit for at least ten minutes and observe their surroundings without being disturbed. Their SitSpot should be in an outdoor, natural environment if possible but if the participants live in a very urban environment, then they are to find a space where they can sit and quietly observe what is happening around them. The teacher candidates cannot have their phone or other digital device turned on during SitSpot time. Instead, they are to take a pen and paper, and observe and describe their surroundings. The SitSpot activity is iterative: the participants should return weekly to the same spot and observe/comment/draw how the environment around their SitSpot is changing over time. Many of the teacher candidates remark that this quiet time in a natural setting allows them not only to observe nature, but also to reflect on their lives; it is a calming, contemplative moment in an otherwise hectic schedule.

The SitSpot assignment aligns with Fabjański and Brymer's (2017) contemplative philosopher state, attuned to the natural world; participants consciously and repeatedly direct their attention to the changes in their surrounding environment as a way to build understanding and connection with that environment. The SitSpot is a simple teaching and learning strategy, yet it requires commitment and concentration on the part of the learner, and a willingness to attune to a singular place.

\section{Final Thoughts}

A walking curriculum does not require striding through many kilometres of countryside. Rather, it must provide significant opportunities for learners to risk leaving their physical, emotional and professional comfort zones in order to move through natural spaces as a way to (re)connect with natural environments and to find out for themselves how they fit into those spaces. The lenses of risk and connection provide a particular perspective, one that supports the walking curriculum that is embedded in the environmental education course I teach. I have described a number of activities that support the concept of a walking curriculum, activities that provide opportunities to take risks, and then reap the benefits of building stronger connections to places and people. In this way, a walking curriculum moves beyond the transactional processes of passing along information. As such, a walking curriculum may become transformative for the learner; world views might shift towards a belief in the interconnectedness of humanity and nature. It has been my experience that a walking curriculum provides a crucial foundation for those who will become teachers. As I walk with teacher candidates through the natural landscape of the forest, as well as the figurative landscapes of 
teaching and learning, we find ourselves becoming attuned to the interconnectedness that we share with each other and with the earth beneath our feet.

\section{About the Author}

Astrid Steele is an associate professor (recently retired) at Nipissing University, with a strong background in outdoor, environmental and sustainability education, and science education. Her current interests are in teacher development in science and environmental education, and in microaggressions related to teaching and learning.

\section{References}

Braun, T., \& Dierkes, P. (2017). Connecting students to nature-how intensity of nature experience and student age influence the success of outdoor education programs. Environmental Education Research, 23(7), 937-949. https://doi.org/10.1080/13504622.2016.1214866

Carter, M. (2007). Making your environment "the third teacher". Exchange, July/August, 22-26.

Fabjański, M., \& Brymer, E. (2017). Enhancing health and wellbeing through immersion in nature: A conceptual perspective combining the stoic and Buddhist traditions. Frontiers in Psychology, 8(1573), 1-6. https://doi.org/10.3389/fpsyg.2017.01573

Geertz, C. (1996). Afterword. In S. Feld \& K. Basso (Eds.), Senses of place (pp. 259-262). School of American Research Press.

Greenwood, D. A. (2009). Place: The nexus of geography and culture. In M. McKenzie, P. Hart, H. Bai, $\&$ B. Jickling (Eds.), Fields of Green: Restorying culture, environment and education (pp. 271282), Hampton.

Howard, S. K. (2011). Affect and acceptability: Exploring teachers' technology-related risk perceptions. Educational Media International, 48(4), 261-272. https://doi.org/10.1080 /09523987.2011.632275

Kabat-Zinn, J. (2013). Full catastrophe living: Using the wisdom of your body and mind to face stress, pain, and illness. Bantam/Random.

Mullenbach, L.E., Andrejewski, R.G., \& Mowen, A.J. (2019). Connecting children to nature through residential outdoor environmental education. Environmental Education Research, 25(3), 365374. https://doi.org/10.1080/13504622.2018.1458215

Naess, A. (1989). Ecology, community and lifestyle. Cambridge University Press.

Renn. O. (2004). Perception of risks. The Geneva papers on risk and insurance, 29(1), 102-114.

Sauvé, L. (2005). Currents in environmental education: Mapping a complex and evolving pedagogical field. Canadian Journal of Environmental Education, 10(1), 11-37. https://cjee.lakeheadu.ca/article/view/175

Slovic, R., Finucane, M. L., Peters, E., \& MacGregor, D. G. (2004). Risk as analysis and risk as feelings: Some thoughts about affect, reason, risk, and rationality. Risk Analysis, 24(2), 311-322. https://doi.org/10.1111/j.0272-4332.2004.00433.x

Slovic, P. (2000). Trust, emotion, sex, politics, and science: Surveying the risk-assessment battlefield. In P. Slovic (Ed.), The perception of risk (pp. 390-412). Earthscan. 
Steele, A., \& Ashworth, E. (2017). From shafts to drifts: Collaborating to strengthen integrated teaching and learning. In D. H. Jarvis \& M. Kariuki (Eds.), Co-teaching in higher education: From theory to practice, (pp. 112-136). University of Toronto Press. 